\title{
TeMP (Tempat Sampah Pintar):Alat Monitoring dan Pendeteksi Kelembaban Sampah Berbasis Mikrokontroller
}

\author{
Syahrir'), Muhajirin Saad $^{2)}$, Asriani' ${ }^{3)}$, Erika Rachma Aprilia ${ }^{4)}$ \\ 1)23)4) Teknik Elektro/Teknik Multimedia dan Jaringan \\ Email:syahrir@poliupg.ac.id ${ }^{1)}$,muhajirinsaad@gmail.com ${ }^{2)}$,aniasriani77@gmail.com ${ }^{3)}$, erikarachma60@gmail.com ${ }^{4)}$
}

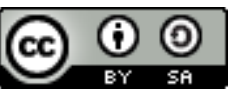

\begin{abstract}
Abstrak
Pengangkutan sampah di Makassar saat ini dilakukan oleh pihak pemerintah kota dan sebuah perusahaan pengelola sampah berbasis aplikasi yaitu PT Mall Sampah Indonesia. Namun masih ditemukan kendala-kendala yang menghambat pengelolaan sampah seperti waktu pengangkutan sampah yang tidak teratur dan jenis sampah yang tidak sesuai pada pengelolaan sampah seperti waktu pengangkutan sampah yang tidak teratur dan jenis sampah yang tidak sesuai pada tempatnya. Berdasarkan masalah tersebut maka penulis merancang sebuah alat yang mampu menjadi solusi dari masalah tersebut. Alat ini menggunakan sensor ultrasonik berbasis mikrokontroler yang diberi nama TeMP(Tempat Sampah Pintar). Penerapan teknologi IoT ini digunakan untuk memudahkan pengepul dari pihak mitra untuk mengambil sampah jika tempat sampah hampir penuh sehingga pengambilan sampah lebih terkontrol. Tempat sampah pintar ini dapat mendeteksi kelembaban sampah.
\end{abstract}

Keywords: Tempat Sampah, Internet of Things, mikrokontroller

\section{PENDAHULUAN}

Sampah adalah sisa kegiatan sehari hari manusia dan/atau dari proses alam yang berbentuk padat (Suyoto, 2008). Dalam kehidupan manusia, sebagian besar aktivitas akan menghasilkan sampah. Sampah tersebut akan menumpuk di tempat pembuangan sampah. Apabila tumpukan yang semakin meningkat tersebut tidak diimbangi dengan pengolahan yang baik maka akan muncul berbagai permasalahan terutama bagi penduduk di sekitar tempat pembuangan sampah tersebut. Beberapa jenis sampah harus dibuang sesegera mungkin dan sejauh mungkin karena dapat membusuk sehingga mengeluarkan bau yang tidak sedap, mengundang bibit penyakit, dan kerugian lainnya. Pengelolaan sampah menjadi salah satu faktor yang mempengaruhi terciptanya lingkungan yang bersih dan sehat. Sampah yang dibiarkan terlalu lama menumpuk dan pengambilan sampah yang tidak teratur menjadi masalah yang sering terjadi di kotakota besar seperti di Kota Makassar. Pengangkutan sampah di Makassar saat ini dilakukan oleh pihak pemerintah kota dan sebuah perusahaan pengelola sampah berbasis aplikasi yaitu PT Mall Sampah Indonesia. PT Mall Sampah Indonesia adalah sebuah perusahaan pengelola sampah yang berdiri pada tahun 2015 di Kota Makassar dengan sistem pengelolaan sampah berbasis aplikasi dengan menerapkan 6 layanan yaitu Jual
Sampah, Donasi Sampah, Produk Hijau, Zero Waste, dan Gerakan Hijau. Berdasarkan wawancara penulis dengan pihak mitra yaitu PT Mall Sampah Indonesia, pengangkutan sampah berbasis aplikasi telah memiliki banyak manfaat dan perubahan yang begitu signifikan, namun masih ditemukan kendala-kendala yang menghambat pengelolaan sampah seperti waktu pengangkutan sampah yang tidak teratur dan jenis sampah yang tidak sesuai pada tempatnya. Berdasarkan masalah tersebut maka penulis merancang sebuah alat yang mampu menjadi solusi dari masalah tersebut. Alat ini menggunakan sensor ultrasonik berbasis mikrokontroler yang diberi nama TeMP(Tempat Sampah Pintar). Alat ini berfungsi untuk memantau apakah sebuah tempat penampungan sampah sudah terisi penuh atau belum dan memberikan pemberitahuan ke pihak pengumpul sampah dalam hal ini pihak mitra yaitu PT Mall Sampah Indonesia melalui Short Message Service(SMS) apabila sampah sudah harus diangkut. Penggunaan sensor ultrasonik pada alat ini adalah sebagai pemantau apakah sebuah tempat penampungan sampah sudah penuh atau belum menggunakan gelombang ultrasonik. Sedangkan water level sensor sebagai pemantau kelembaban sampah dengan ini dapat diketahui sampah yang masuk adalah sampah basah atau kering. 


\section{KAJIAN LITERATUR}

Penelitian mengenai pembuatan tempat sampah telah banyak dilakukan, seperti pada penelitian dengan judul "Kotak Sampah Pintar Menggunakan Sensor Ultrasonik" oleh Muhammad A.M Nabil. . Pada penelitian tersebut menggunakan sensor ultrasonic untuk mendeteksi jarak sampah ketika sudah penuh serta RTC dan SDCard untuk penyimpanan data log. Namun belum dilengkapi fitur pendeteksi sampah basah dan kering. Berdasarkan hal tersebut maka penulis membuat alat monitoring sampah yang mampu mendeteksi sampah basah dan kering menggunakan Water Level Sensor. Penggunaan Water Level Sensor mampu memberikan edukasi agar sampah dapat dibuang sesuai pada tempatnya.

\section{A. Mikrokontroller Arduino Uno R3}

Mikrokontroler merupakan suatu terobosan teknologi mikroprosesor dan juga mikrokomputer. Sebagai teknologi baru, yaitu teknologi semikonduktor dengan kandungan transistor yang lebih banyak namun hanya membutuhkan ruang yang kecil (Putra, 2003). Dalam website arduino.cc, disebutkan bahwa Arduino Uno adalah sebuah platform elektronik berbasis open source yang mudah digunakan pada perangkat keras maupun perangkat lunak. Arduino adalah sebuah komputer kecil yang dapat diprogram sebagai input dan output dengan bantuan alat sebagai hasilnya. Arduino pertama kali ditemukan pada tahun 2005 oleh Massimo Banzi dan David Cuartielles yang mencoba membuat sebuah proyek untuk membuat perangkat untuk mengendalikan dari proyek yang dibuat oleh mahasiswa pada waktu itu dengan harga yang lebih murah dari harga perangkat yang tersedia pada saat itu (Lahart, 2017). Arduino mempunyai banyak seri. Dalam sistem ini penulis menggunakan salah satunya, yaitu Arduino Uno. Arduino Uno adalah papan mikrokontroler yang berbasis mikrokontroler ATmega328[6][7]:

Arduino yang terbaru adalah seri UNO R3. Arduino ini berbeda dari semua board Arduino Uno sebelumnya, Arduino Uno tidak menggunakan chip driver FTDI USB-to-serial (McRobert, 20detedbgdb10). Arduino Uno terbaru pada saat ini adalah perbaruan yang ketiga atau bisaa disebut dengan Arduino Uno R3 seperti gambar 2.2. Arduino Uno R3 memiliki spesifikasi sebagai berikut:

a. Mikrokontroler ATmega328. b. Beroperasi pada tegangan 5V. c. Tegangan yang didukung 7-12 V. d. Batas tegangan 6-20 V. e. Digital I/O 14 pin. f. Analog input 6 pin. g. Flash memori $32 \mathrm{~KB}$ (ATmega 328). h. SRAM $2 \mathrm{~KB}$ (ATmega 328) i. EEPROM $1 \mathrm{~KB}$ (ATmega 328). j. Clock speed $16 \mathrm{MHz}$.

\section{B. Kabel Jumper}

Jumper adalah kabel yang lazimnya di gunakan sebagai penghubung antara Arduino Uno dengan board atau Arduino Uno dengan sensor yang akan digunakan. Kabel jumper menghantarkan listrik atau sinyal. Ada tiga jenis kabel jumper yang dapat dilihat dari ujungnya, yaitu: a. Male-Male b. Male-Female c. Female-Female

\section{Sensor Ultrasonik}

Modul sensor Ultrasonik ini dapat mengukur jarak antara $3 \mathrm{~cm}$ sampai $300 \mathrm{~cm}$. Keluaran dari modul sensor ultrasonik PING ini berupa pulse yang lebarnya merepresentasikan jarak. Lebar pulsenya yang dihasilkan modul sensor ultrasonik ini bervariasi dari $115 \mathrm{uS}$ sampai $18,5 \mathrm{mS}$. Secara prinsip modul sensor ultrasonik ini terdiri dari sebuah chip pembangkit sinyal $40 \mathrm{KHz}$, sebuah speaker ultrasonik dan sebuah mikrofon ultrasonik. Speaker ultrasonik mengubah sinyal $40 \mathrm{KHz}$ menjadi suara sementara mikrofon ultrasonik berfungsi untuk mendeteksi pantulan suaranya.

\section{Modul GSM}

Global System for Mobile communication (GSM) adalah sebuah standar global untuk komunikasi bergerak digital. Teknologi ini memanfaatkan gelombang mikro dan pengiriman sinyal yang dibagi berdasarkan waktu, sehingga sinyal informasi yang dikirim akan sampai pada tujuan. GSM dijadikan standar global untuk komunikasi selular sekaligus sebagai teknologi selular yang paling banyak digunakan orang di seluruh dunia. (Chamim, 2010). Modul GSM merupakan bagian dari pusat kendali yang berfungsi sebagai transceiver, mempunyai fungsi yang sama dengan sebuah telepon seluler yaitu mampu melakukan fungsi pengiriman dan peneriman SMS. Dengan adanya sebuah modul GSM maka aplikasi yang dirancang dapat dikendalikan dari jarak jauh dengan menggunakan jaringan GSM sebagai media akses.

\section{E. Water Level Sensor}

Water Level Sensor adalah alat yang digunakan untuk memberikan signal kepada alarm / automation panel bahwa permukaan air telah mencapai level tertentu. Sensor akan memberikan signal dry contact (NO/NC) ke panel. Detector ini bermanfaat untuk memberikan alert atau untuk menggerakkan perangkat automation lainnya. Water sensor ini telah dilengkapi dengan built-in buzzer yang berbunyi pada saat terjadi trigger. Sensor ketinggian air biasanya digunakan untuk menghitung ketinggian air di sungai, danau, atau tangki air. Sensor ini sangat mudah untuk dibuat karena bahan - bahanya sederhana. 


\section{METODE PENELITIAN}

Pelaksanaan penelitian ini, dibagi menjadi 4 tahapan, yaitu tahap persiapan, tahap pembuatan alat, tahap impelementasi alat ke mitra, dan tahap laporan kemajuan, akhir dan presentasi.

\section{HASIL DAN PEMBAHASAN}

TeMP yang akan diterapkan di PT Mall Sampah dinilai sudah berjalan sesuai jadwal dengan semua alat berfungsi dengan baik mulai dari alat monitoring hingga pendeteksi kelembaban. Langkah awal dari pembuatan alat ini adalah survei awal dan studi literatur agar bisa mengetahui hal-hal apa yang dibutuhkan untuk mendapatkan solusi dari masalah mitra. Kemudian analisa kebutuhan dilakukan agar sistem alat bisa lebih tepat guna. Selanjutnya perangkaian alat dan pembuatan program monitoring dan pendeteksi kelembaban. Setelah selesai, rangkaian disusun ke dalam satu box dan dipasang di tempat sampah.

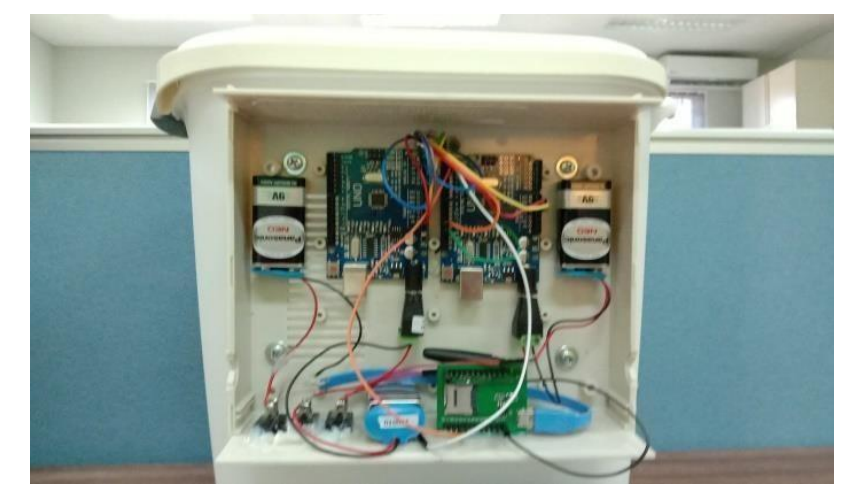

Gambar 1. Rangkaian TeMP

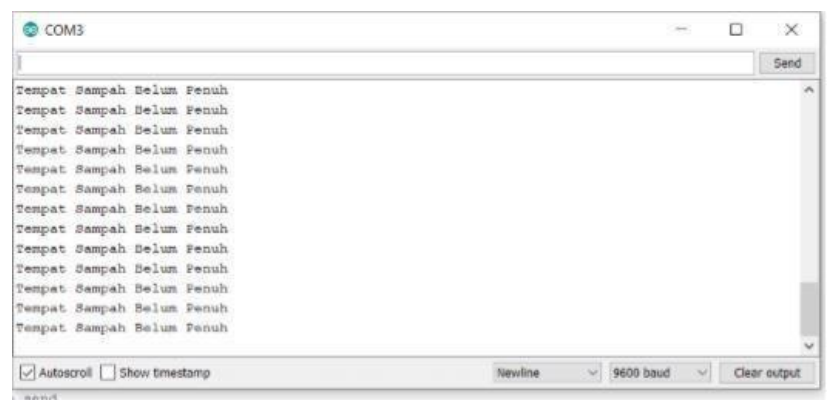

Gambar 2. Pengujian Tempat Sampah Belum Penuh

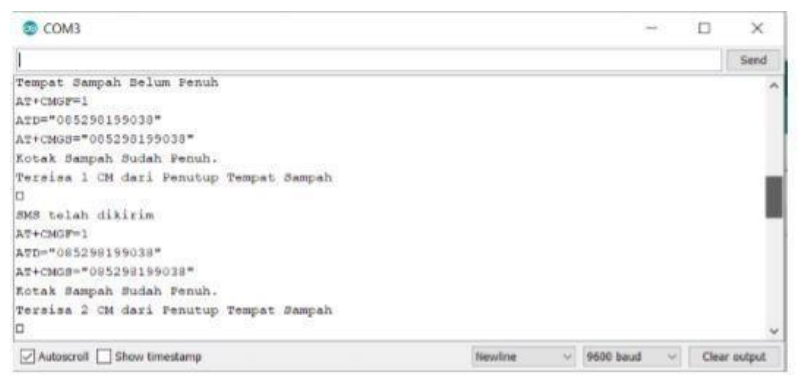

Gambar 3. Uji SMS dan Telepon
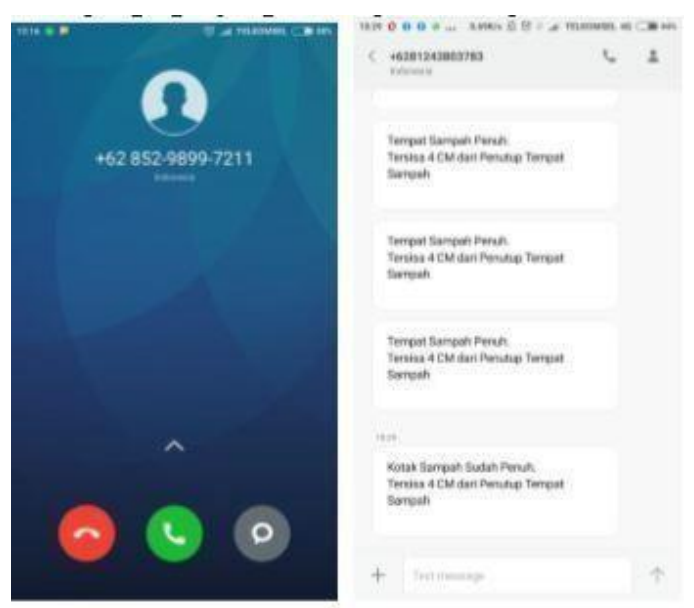

Gambar 4. Hasil Pengingat yang Masuk pada Telepon

\section{KESIMPULAN}

Penelitian ini dilakukan untuk mengetahui hasil penerapan teknologi IoT agar memudahkan pengepul dari pihak mitra untuk mengambil sampah jika tempat sampah hampir penuh sehingga pengambilan sampah lebih terkontrol. Tempat sampah pintar ini dapat mendeteksi kelembaban sampah. Selain itu tampat sampah pintar ini dapat menjadi produk yang dapat digunakan untuk mendukung sistem PT Mall Sampah Indonesia.

\section{UCAPAN TERIMA KASIH}

Pada kesempatan ini penulis mengucapkan banyak terima kasih kepada semua pihak yang telah banyak memberikan dorongan positif kepada penulis baik langsung maupun tidak langsung. penulis berharap semoga penelitian ini dapat berguna dan bermanfaat terutama bagi pihak-pihak yang tertarik untuk mengkaji dan mengembangkannya.

\section{REFERENSI}

[1] Arduino. (2017, November 20). arduino-uno-rev3. Diambil kembali dari Arduino.cc: https://store.arduino.cc/usa/arduino-uno-rev3

[2] Elecrom. (2017, November 20). Elecrom.com. Diambil kembali dari Elecrom.com: 
http://www.elecrom.com/introduction-arduinouno-uses-avr-atmega328/

[3]Instruments, D. (2017, November 20). 2016/02/23. Diambil kembali dari depokinstruments.com: https://depokinstruments.com/2016/02/23/hcsr04ultrasonicsensor/

[4] Kedairobot. (2017, November 20). All products. Diambil kembali dari kedairobot.com:http://kedairobot.com/allproducts/12-arduino-jumpercables.html

[5] Muhammad A M N. 2018. Kotak Sampah Pintar Menggunakan Sensor Ultrasonik Berbasis Mikrokontoller Arduino Uno. Skripsi. Tidak Diterbitkan. Fakultas Teknologi Industri. Universitas Islam Indonesia; Yogyakarta.

[6] A Apollo, M Marhatang, A Rahman, 2017, Rancang Bangun Sistim Kendali Rumah Cerdas, Jurnal Teknologi Elekterika 14 (2), 182-190, ISSN 1412-8764

[7] D Kambuno, M Nurdin, S Syahrir, Z Abidin, 2017, Pengembangan Soft Starting Dengan Kontrol PID Pada Motor Induksi Berbasis Mikrokontroller, Jurnal Teknologi Elekterika 14 (2), 174-181, ISSN 14128764 